\title{
CAVERNOUS HEMANGIOMA OF THE RIGHT ATRIUM: Presumptive Diagnosis By Coronary Angiography
}

\author{
Daniel S. Raabe, Jr., M.D., John C. Fischer, M.D., and Ralph L. \\ Brandt, M.D.
}

The anglographic findings in a patient with an interesting vascular tumor of the right atrium are described. The tumor was supplied by vessels from both the right and left coronary arteries and consisted of dilated blood spaces in which contrast material persisted for a prolonged period of time.

Since this picture is identical to that described in cavernous hemangioma of other organs, this report presumably represents the first description of the angiographic findings in a cavernous hemangioma of the heart.

Key words: cardiac tumor, cavernous hemangioma, coronary angiography

\section{INTRODUCTION}

Cavernous hemangiomas of the heart are rare tumors. They are usually discovered incidentally at autopsy; to our knowledge, the angiographic description of this tumor has not been reported. We therefore describe a patient with a vascular tumor of the right atrium discovered during coronary angiography. The angiographic characteristics of this tumor are identical to those described in cavernous hemangiomas of other organs.

\section{Case report}

For 3 months prior to admission E.W., a 52-year-old white female, had noted increasing fatigue, substernal tightness, and mild dyspnea which would occur with exertion and last for 15 to $30 \mathrm{~min}$. The patient had smoked one pack of cigarettes per day for 30 years and had a 7 year history of adult onset diabetes mellitus controlled with diet.

Physical examination revealed a well-nourished white female with a blood pressure of $130 / 70$ and ventricular rate of 80 . The physical examination was normal; in particular no significant cardiac murmurs were heard.

From the University of Michigan and St. Joseph Mercy Hospital, Ann Arbor, Michigan

Reprint requests to: Daniel S. Raabe, Jr., M.D., Cardiology Unit, Medical Center Hospital of Vermont, Burlington, VT 05401

Received May 18, 1976; revision accepted July 12, 1976 
TABLE I. Catheterization Data

\begin{tabular}{lcc}
\hline & Pressure (mmHg) & $\mathrm{O}_{2}$ Saturation $(\%)$ \\
\hline SVC & & 78 \\
IVC & 2 & 85 \\
RA (mean) & $24 / 2$ & 82 \\
RV & $24 / 10$ & 81 \\
PA & 3 & 82 \\
PAW & $120 / 78$ & \\
AsAo & $120 / 9$ & 95 \\
LV & \\
\hline
\end{tabular}

AsAo $=$ Ascending aorta

IVC = Inferior vena cava

LV $=$ Left ventricle

PA = Pulmonary artery

PAW = Pulmonary artery wedge

RA = Right atrium

$\mathrm{RV}=\mathrm{Right}$ ventricle

$\mathrm{SVC}=$ Superior vena cava

The electrocardiogram and chest $\mathbf{x}$-ray were normal. Cardiac fluoroscopy demonstrated a curvilinear area of calcium in the region of the right atrial appendage. The echocardiogram was normal; in particular there was no evidence of right ventricular volume overload.

Cardiac catheterization was performed using the percutaneous femoral approach. Hemodynamic data and oxygen saturations are shown in Table I. The pressures were normal and there was no significant step-up in oxygen saturation detected in the right heart. Left ventricular angiography was performed with the patient in the $30^{\circ}$ right anterior oblique position. The left ventricle was of normal size and left ventricular contraction was normal. The ejection fraction was $68 \%$. Coronary angiography revealed normal coronary arteries. However, a large vascular tumor was seen in the area of the right atrial appendage. This tumor was supplied by large, normal-appearing vessels from the left anterior descending, left circumflex, and right coronary arteries (Figs. 1,2), and consisted of large vascular channels which retained contrast material for a prolonged period of time (Fig. 3). The tumor was well circumscribed with a calcified superior margin. There was no evidence of vascular encasement and the vessels supplying the tumor appeared to taper normally.

In order to localize this tumor further, contrast material was injected into the superior vena cava. The right ventricle, left atrium, and left ventricle were normal. There was a filling defect in the area of the right atrial appendage. (Fig. 4).

After completion of the right coronary angiograms a Swan-Ganz thermodilution catheter was positioned high in the right atrium; when $5 \mathrm{ml}$ of cold saline was injected into the right coronary artery, the thermistor in the right atrium registered almost immediate temperature change, indicating a rapid left to right shunt through the tumor. 

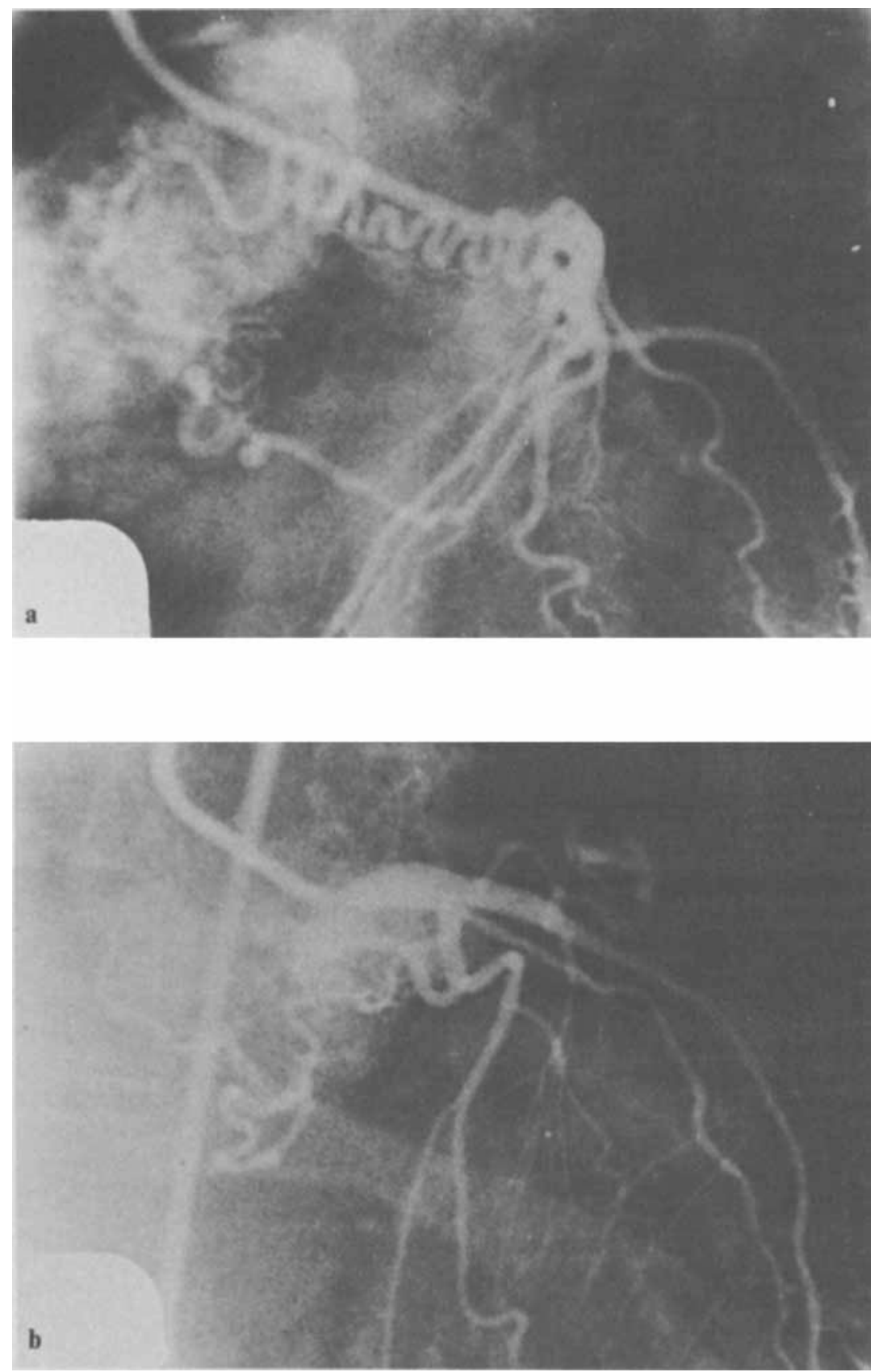

Fig. 1a. LCA in LAO projection. The coronary arteries are normal. A large vascular tumor lies anteriorly and is supplied by 2 vessels. The upper vessel arises from the LAD while the lower vessel originates from the LCCA. This is best seen in the RAO projection (Fig. 1b). (LAD = left anterior descending coronary artery; LAO = left anterior oblique; LCA = left coronary artery; LCCA = Ieft circumflex coronary artery; RAO = right anterior oblique.) 


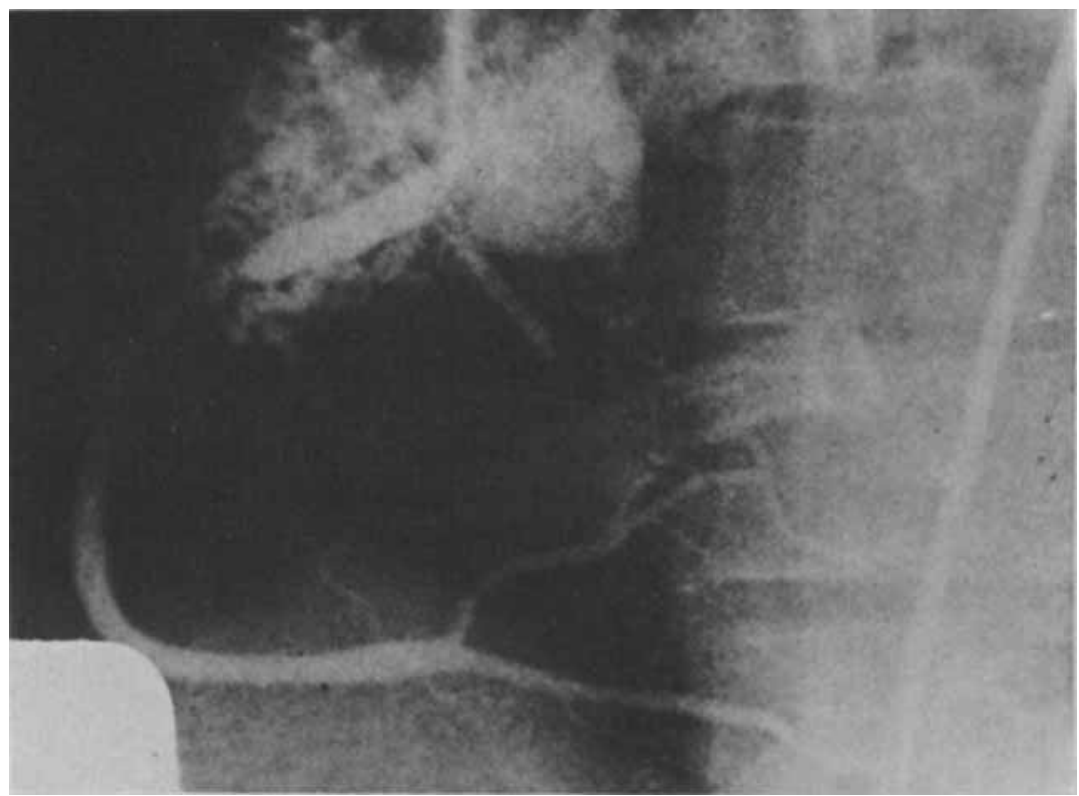

Fig. 2. RCA in LAO projection. The tumor is also supplied by the RCA and consists of large dilated blood spaces. (RCA = right coronary artery.)

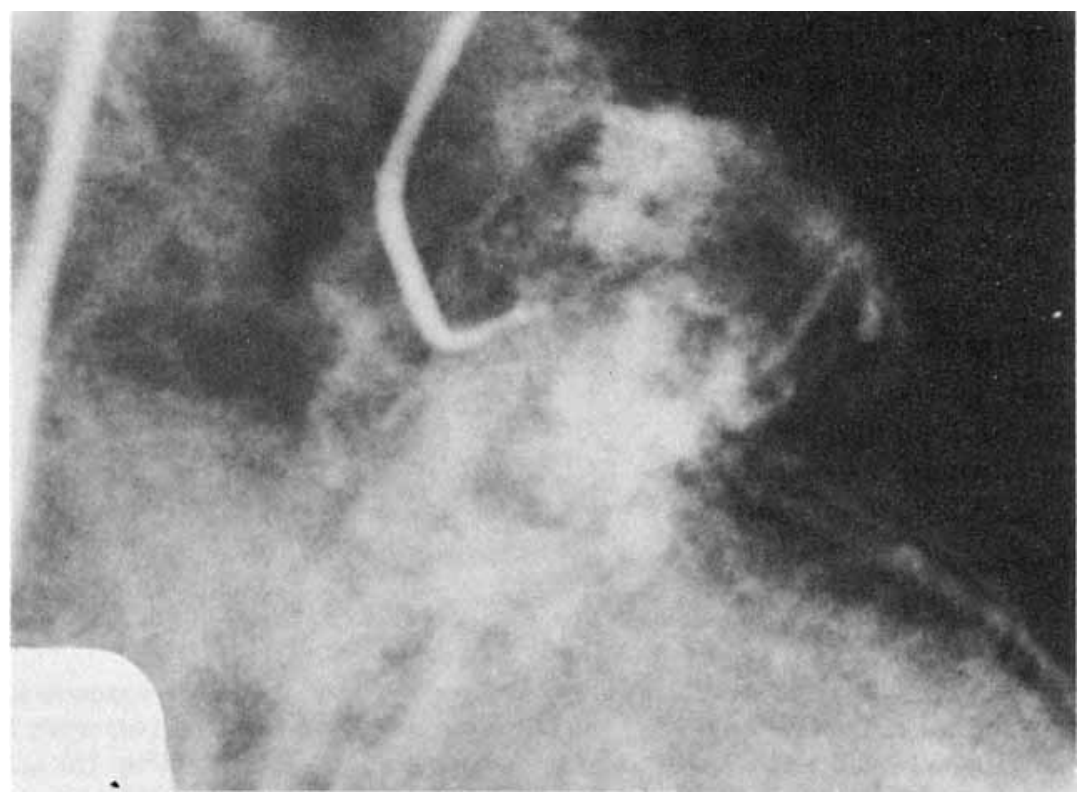

Fig. 3. LCA in RAO. Contrast material remains in the tumor after it has been cleared from the LCA and its branches. 


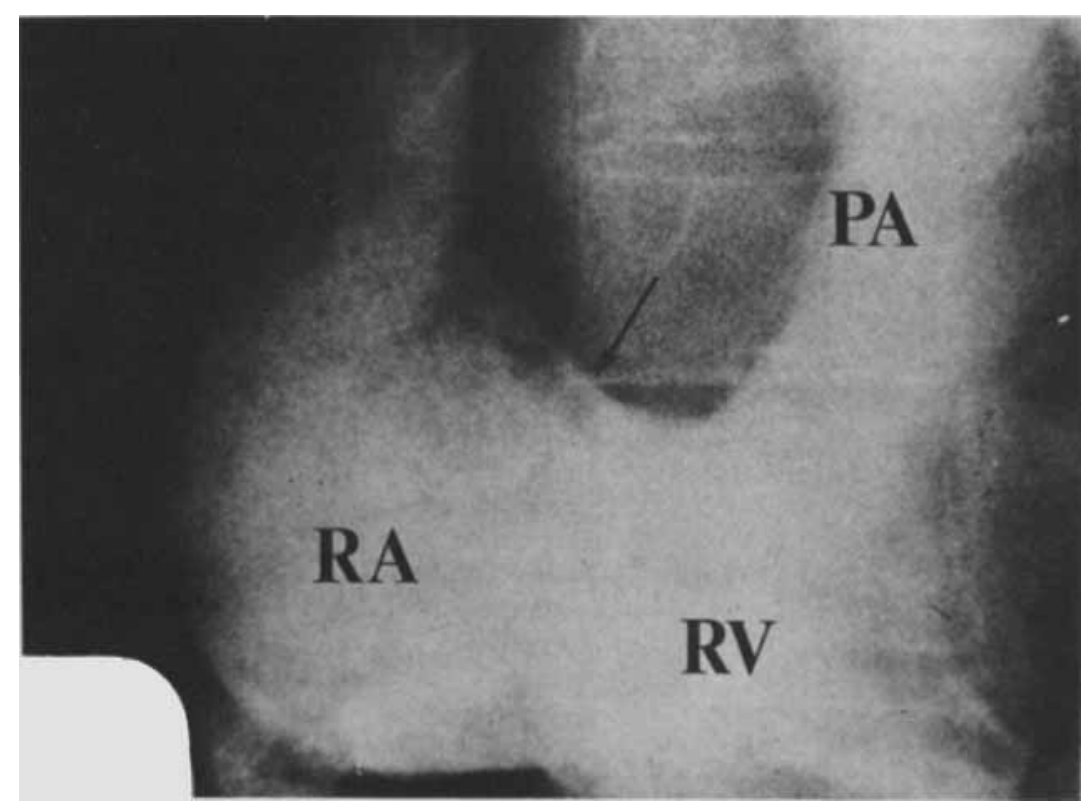

Fig. 4. The right atrial appendage (arrow) contains no contrast material despite the fact that enough contrast material has been injected to fill the right atrium (RA), right ventricle (RV), and pulmonary artery (PA).

When the patient was reexamined after the catheterization results were known, A Gr I/VI continous, high-pitched murmur could be heard in the third intercostal space at the left sternal border with the patient in the standing position.

\section{DISCUSSION}

Cavernous hemangiomas are exceedingly uncommon primary cardiac tumors. Mahaim (1), in 1945 and Pritchard (2) in 1951 were able to find 5 cases in the world literature. In 1964 Peychl (3) reported a cavernous hemangioma of the left ventricle and described 17 other reported cases. A review of the literature now reveals an additional 5 patients $(2,6,7,8,9)$. Our case is thus the 24th report of a cavernous hemangioma of the heart.

Table II outlines some of the characteristics of these cases. The tumor occurs in all age groups with a marked male predominance. The right atrium is the most frequent site. In approximately $50 \%$ of the cases the patients are asymptomatic. However, intracavitary tumors can produce valvular insufficiency (3) or obstruction $(6,7)$. In the case reported by Grant $(9)$, a septal tumor destroyed the bundle of His and produced complete atrioventricular block. Of interest is the case reported by Panbruccian (7) of a 55-year-old male who presented with the clinical and electrocardiographic picture of an acute anteroseptal myocardial infarction. At autopsy he was found to have a cavernous hemangioma of the interventricular septum and no evidence of a recent infarction. Our patient presented with chest 
TABLE II. Reported Cases of Cardiac Hemangiomas

\begin{tabular}{|c|c|c|c|c|}
\hline Author & Sex & Age & Location & Symptoms \\
\hline Uskow ${ }^{3}$ & $?$ & $?$ & Heart & $?$ \\
\hline Czapek $^{8}$ & $\mathbf{M}$ & 56 & Subepicardial left ventricle & 0 \\
\hline Borchow ${ }^{3}$ & $\mathbf{M}$ & 61 & Left atrium & Mitral insufficiency \\
\hline Bostroem $^{3}$ & $?$ & 3 weeks & Right atrium & Cyanosis \\
\hline $\mathrm{Rau}^{2}$ & M & 56 & Right atrium & 0 \\
\hline Train ${ }^{2}$ & $M$ & 78 & Left atrium & 0 \\
\hline $\operatorname{Koch}^{8}$ & $M$ & 51 & $\begin{array}{l}\text { Subepicardial interven- } \\
\text { tricular sulcus }\end{array}$ & 0 \\
\hline Eichtweiss $^{8}$ & M & 54 & Right atrium & 0 \\
\hline Schuster ${ }^{2}$ & $?$ & 1 month & $\begin{array}{l}\text { Right ventricle } \\
\text { (papillary muscle) }\end{array}$ & 0 \\
\hline Manifold ${ }^{3}$ & $\mathrm{~F}$ & 54 & Left atrium & Harsh murmur, seizures \\
\hline Runge $^{3}$ & $?$ & 10 days & $\begin{array}{l}\text { Subepicardial left } \\
\text { ventricle }\end{array}$ & 0 \\
\hline Soria $^{7}$ & $\mathrm{~F}$ & 42 & Left atrium & Mitral stenosis \\
\hline Grant $^{9}$ & M & 39 & Septum & Complete heart block \\
\hline $\operatorname{Link}^{3}$ & $\mathrm{~F}$ & "old" & Right atrium & Abnormal EKG \\
\hline Greenberg $^{10}$ & M & 63 & $\begin{array}{c}\text { Subepicardial atrio- } \\
\text { ventricular sulcus }\end{array}$ & 0 \\
\hline Hochberg $^{11}$ & $\mathrm{~F}$ & 8 & Right atrium & Fatigue, dyspnea \\
\hline Pritchard ${ }^{2}$ & M & 38 & Right atrium & 0 \\
\hline Reiner $^{8}$ & M & 61 & $\begin{array}{l}\text { Subepicardial right } \\
\text { ventricle }\end{array}$ & 0 \\
\hline Peychl ${ }^{3}$ & M & 70 & $\begin{array}{l}\text { Subepicardial left } \\
\text { ventricle }\end{array}$ & Congestive heart failure \\
\hline Baroldi $^{4}$ & M & 24 & Right atrium & Congestive heart failure \\
\hline Plemenac 5 & M & 37 & Right atrium & 0 \\
\hline Delaye $^{6}$ & M & 23 & Right ventricle & $\begin{array}{l}\text { Congestive heart failure, } \\
\text { pulmonic stenosis }\end{array}$ \\
\hline Pambuccian 7 & $\mathbf{M}$ & 55 & Septum & Myocardial infarction \\
\hline Raabe & $\mathrm{F}$ & 52 & Right atrium & $\begin{array}{l}\text { Chest pain, abnormal } \\
\text { chest } x \text {-ray }\end{array}$ \\
\hline
\end{tabular}

pain which had some of the characteristics of angina pectoris. We do not believe that her pain is due to coronary insufficiency secondary to the tumor since the left to right shunt through the tumor is small and unlikely to cause a "coronary steal", syndrome.

In only 3 previous cases has the diagnosis of a "cardiac tumor" been made pre-mortem; in each instance the type of tumor was discovered only by thoracotomy or at post-mortem $(4,6,11$.) In 2 of these 3 cases the tumor was removed at operation. In Hochberg's case (11) a large tumor involving the epicardium of the right atrium and the overlying pericardium was successfully removed, and in the case reported by Delaye (6) a pedunculated tumor was removed from the right ventricle with relief of right ventricular outflow obstruction. Because of our patient's relative lack of symptoms and because the extensive blood supply of this tumor would make excision difficult, we have elected not to advise operation. 
Although histologic proof is unavailable, we have no doubt that this tumor is a cavernous hemangioma. It has all of the angiographic characteristics of cavernous hemangioma as it has been described in other visceral organs $(12,13,14$ (i.e., a well-circumscribed vascular tumor supplied by normal-appearing arteries, consisting of dilated blood spaces in which contrast material persists for a prolonged period of time). It does not show the angiographic characteristics of the malignant hemangiosarcoma as described by Moss, et al. (15) Presumably, therefore, this case represents the first reported instance of a cavernous hemangioma of the heart diagnosed by coronary angiography.

\section{REFERENCES}

1. Mahaim I: Les tumeurs et les polypes de coeur: E'tude anatomo-clinique. Masson et Cie., Paris, and F. Roth et Cie, Lausanne, 1045. Cited in Pambuccian, et al. (See reference \#7)

2. Pritchard RW: Tumors of the heart. Arch Path (Chicago) 51:98-118, 1951.

3. Peychl L: Kavernoses herzhamangiom. Zbl Allg Path 105:365-370, 1964.

4. Baroldi G, Colombo F and Manion W: Benign primary hemangioma of the right atrium of the heart. Med Ann of D.C. 36:287-290, 1967.

5. Plemenac P, Pikula B and Selak I: Une observation p'hemangiome intracordiaque. Le Poumon et le Coeur 27:449-453, 1971.

6. Delaye J, Rogues JC, Crassard P, Loire R, Berthon JD and Gonin A: Les tumeurs primitives du ventricle droit. Coeur et Med Interne 597:11-16, 1972.

7. Pambuccian GR and Bercovici S: Angioma of the heart with a picture of myocardial infarct. Rom Med Rev 13:9-13, 1969.

8. Reiner L and Silberg N: Cavernous hemangioma of the epicardium. Am J Path 29:1133-1141, 1953.

9. Grant RT and Camp PD: A case of complete heart block due to an arterial angioma. Heart 16:137-143, 1932.

10. Greenburg $M$ and Angrest A: Primary vascular tumors of the pericardium. Am Heart J 35:623-634. 1948.

11. Hochberg L and Robinson A: Primary tumor of the pericardium involving the myocardium: Surgical removal. Circulation 1:805-808, 1950.

12. Abrams RM, Berenbaum ER, Santos JS and Lipsom J: Angiographic features of cavernous hemangioma of the liver. Radiology 92:308-312, 1969.

13. McLaughlin MJ: Angiography in cavernous hemangioma of the liver. Am J Roent Rad Ther and Nuc Med 113:50-55, 1971.

14. Rosenthal T, Adar R, Wolfstein R and Deutsch V: Cavernous hemangioma of the spleen: Angiographic observations. Angiology 24:430-433, 1973.

15. Moss A, Clark RE, Palubinskas AJ and DeLorimier AA: Angiographic appearance of benign and malignant hepatic tumors in infants and children. Am J Roent Rad Ther and Nuc Med 113:61-69, 1971. 